\title{
Controlling Mechanisms of Creep Deformation of New Air-Hardenable TiAl-Based Alloy
}

\author{
H. Staneková, J. Lapin* and T. Pelachová \\ Institute of Materials and Machine Mechanics, Slovak Academy of Sciences \\ Račianska 75, 83102 Bratislava, Slovak Republic
}

\begin{abstract}
In the present work, controlling mechanisms of creep deformation of a new cast air-hardenable $\mathrm{Ti}-46 \mathrm{Al}-8 \mathrm{Ta}$ [at.\%] alloy was studied. Long-term constant load tensile creep tests combined with an abrupt change of the applied stress were performed at $700{ }^{\circ} \mathrm{C}$. The response of the alloy to a stress reduction is analyzed. Transient behaviour with zero creep before recommencing creep at a reduced load is related to possible creep deformation mechanisms. The dislocation microstructures are analysed for creep strains corresponding to the minimum creep rate by transmission electron microscopy. The controlling mechanisms of creep deformation are identified from the transient creep behaviour of the alloy during stress reduction, the stress exponent and dislocation microstructures observed after creep testing.
\end{abstract}

PACS: $61.72 .-\mathrm{y}, 62.20 . \mathrm{F}-, 62.40 .+\mathrm{i}, 81.30 . \mathrm{Mh}, 83.50 .-\mathrm{v}$

\section{Introduction}

Cast TiAl-based alloys represent an important class of high-temperature structural materials providing a unique set of physical and mechanical properties for automotive engines, stationary gas turbines and aircraft engines. These outstanding mechanical properties result mainly from the fact that the as-cast microstructures consist of well aligned $\alpha_{2}\left(\mathrm{Ti}_{3} \mathrm{Al}\right)$ and $\gamma(\mathrm{TiAl})$ lamellae [1]. Reducing the grain size in cast samples has been shown to improve significantly room-temperature ductility without degradation of the creep resistance [2]. $\mathrm{Hu}$ et al. [3] showed that Ta has low diffusion coefficients in both $\alpha$ (Ti-based solid solution) and $\gamma$ phases and favours the massive transformation over the lamellar formation at low cooling rates. Based on this concept, an "air-hardenable" Ti-46Al-8Ta [at.\%] alloy, requiring only air cooling from the single $\alpha$ phase field to reduce the grain size of the cast components via formation of massive $\gamma_{\mathrm{M}}(\mathrm{TiAl})$, was designed $[3,4]$. Potential industrial applications of this alloy are conditioned by optimisation of processing techniques $[5,6]$ and a more complex understanding of mechanical properties including creep at operating temperatures.

Several mechanisms operative in the creep deformation of TiAl-based alloys have been proposed in the literature including dislocation activity (glide and climb), grain-boundary sliding, mechanical twinning, and dynamic recrystallization, which are quite sensitive to the constituting phases, microstructural morphologies, and test

\footnotetext{
* corresponding author; e-mail: umms lapi@savba.sk
}

conditions $[7,8]$. In many alloys, creep controlling processes can be identified by observing the value of stress exponent and the type of dislocation structure. However, supplementary techniques are necessary to use to identify creep mechanisms in many TiAl-based alloys because the stress exponent usually changes gradually with increasing stress [9]. Stress reduction test has been widely used to identify the controlling mechanisms or to measure internal stresses during creep of metallic materials. The presence or absence of an incubation period of zero creep in a stress reduction test can assist in determining whether mechanisms based on dislocation recovery (incubation period) or glide (no incubation period) control the creep of the alloy [10]. In spite of recent studies on creep of Ti-46Al-8Ta [at.\%] alloy [11, 12], transient creep behaviour after a stress reduction and deformation microstructures after creep at an operating temperature of $700{ }^{\circ} \mathrm{C}$ have not been reported yet.

The aim of the present work is to identify controlling mechanisms of creep deformation of cast intermetallic Ti-46Al-8Ta [at.\%] alloy using stress reduction test, analysis of dislocation structure and experimental measurements of stress exponent.

\section{Experimental procedure}

Cylindrical Ti-46Al-8Ta [at.\%] bars with a diameter of $13 \mathrm{~mm}$ and length of $120 \mathrm{~mm}$ were prepared from a plasma melted ingot prepared by IRC Birmingham [13] using centrifugal casting into ceramic moulds at ACCESS (Germany) [14]. The cast bars were subjected to thermomechanical heat treatment consisting of hot isostatic 
pressing (HIP) at an applied pressure of $200 \mathrm{MPa}$, temperature of $1260^{\circ} \mathrm{C}$ for $4 \mathrm{~h}$, which was followed by solution annealing at $1360^{\circ} \mathrm{C}$ for $1 \mathrm{~h}$ and air cooling. The heat treatment was finalized by HIP ageing at an applied pressure of $150 \mathrm{MPa}$ and temperature of $1260^{\circ} \mathrm{C}$ for $2 \mathrm{~h}$ followed by cooling at a rate of $5{ }^{\circ} \mathrm{C} / \min [15]$.

Cylindrical creep specimens with a gauge diameter of $6 \mathrm{~mm}$, gauge length of $30 \mathrm{~mm}$ and two ledges for attachment of high temperature extensometer were lathe machined from the as-received bars. The surface of the gauge section was polished to a roughness of about $0.3 \mu \mathrm{m}$. Creep tests were performed at a temperature of $700{ }^{\circ} \mathrm{C}$ under initial applied stresses ranging from 250 to $400 \mathrm{MPa}$. The specimen displacement was measured using a high-temperature extensometer attached to the ledges of the specimen. Continuous data acquisition and processing of time-elongation data was accomplished by a computer.

Microstructure evaluation of creep specimens was performed before and after testing by backscattered scanning electron microscopy (BSEM) and transmission electron microscopy (TEM). Metallographic preparation of samples consisted of standard grinding using abrasive papers, polishing on diamond pastes with various grain sizes up to $0.25 \mu \mathrm{m}$. TEM samples were mechanically thinned to a thickness of about $50 \mu \mathrm{m}$. The thinning continued in a solution of $300 \mathrm{ml} \mathrm{CH} \mathrm{CH}_{3} \mathrm{OH}, 175 \mathrm{ml}$ 2-butanol and $30 \mathrm{ml} \mathrm{HClO}_{4}$ at a temperature of $-10^{\circ} \mathrm{C}$ and voltage of $40 \mathrm{~V}$ until sample perforation. Volume fractions of coexisting phases and the size of lamellar colonies were determined from digitalized micrographs using a computer image analyser.

\section{Results and discussion}

Figure 1 shows the microstructure of $\mathrm{Ti}-46 \mathrm{Al}-8 \mathrm{Ta}$ [at.\%] before creep. The convoluted $\alpha_{2}+\gamma$ microstructure of the as-received material consists mostly of the plate-like $\alpha_{2}$ phase (bright grey contrast) which forms small colonies within the $\gamma$ phase [15]. As shown by Saage et al. [4], this type of microstructure is formed by precipitation of the $\alpha$ and/or $\alpha_{2}$ phases on four equivalent $\{111\}$ planes of the massively transformed $\gamma_{\mathrm{M}}$ during the second HIP-ing at $1260{ }^{\circ} \mathrm{C}$ and cooling from two-phase $\alpha+\gamma$ field. It should be noted that because of the convoluted type of microstructure of the studied alloy, the parameters usually used for microstructure quantification such as colony size, lath distance, etc. are difficult to assess. Therefore, the microstructure is characterised by the volume fraction of coexisting phases and mean length of the $\alpha_{2}$ laths measured from BSEM images such as that shown in Fig. 1. For the heat treated alloy before creep, mean length and average volume fraction of the $\alpha_{2}$ laths are measured to be $(8.5 \pm 0.3) \mu \mathrm{m}$ and $(29.8 \pm 1.3)$ vol.\%, respectively [15].

Figure 2 shows the variation of the creep rate with strain. During the primary creep stage the creep rate decreases with increasing strain. After reaching a minimum

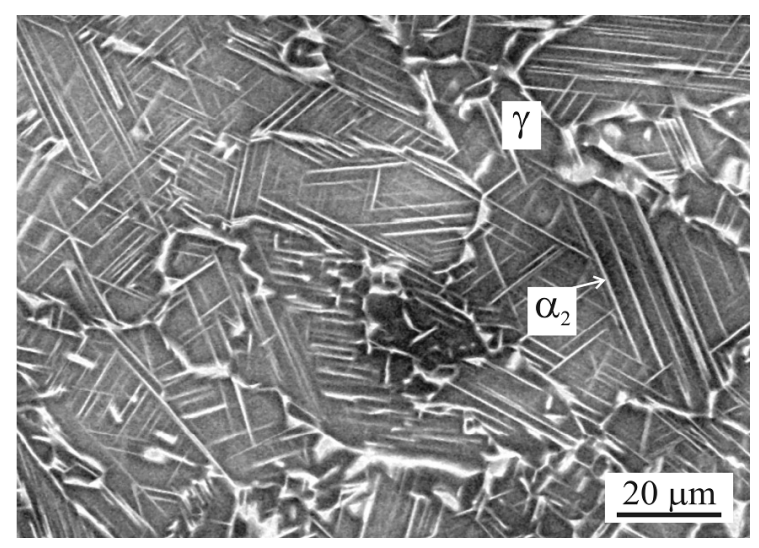

Fig. 1. BSEM micrograph showing the microstructure of the Ti-46Al-8Ta [at.\%] alloy before creep.

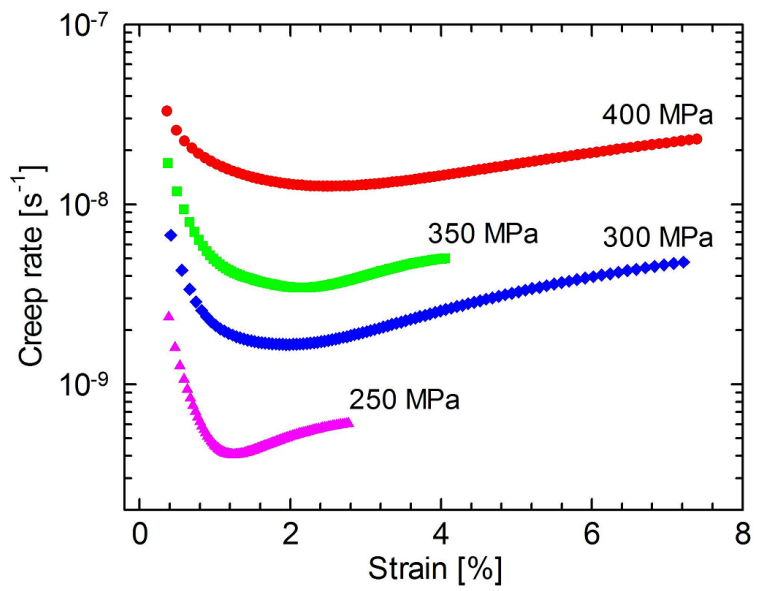

Fig. 2. Dependence of creep rate on strain at $700{ }^{\circ} \mathrm{C}$. The applied stresses are indicated in the figure.

value at a strain ranging from 1.2 to $2.6 \%$, the creep rate increases with increasing strain. No steady-state creep stage is observed in the tests performed at $700{ }^{\circ} \mathrm{C}$ and applied stresses ranging from 250 to $400 \mathrm{MPa}$. The minimum creep rates $\dot{\varepsilon}_{\min }$ and applied stresses $\sigma$ were fitted to the power law

$\dot{\varepsilon}_{\text {min }}=A \sigma^{n}$,

where $A$ is a material constant and $n$ is the stress exponent.

Figure 3 shows the dependence of the minimum creep rate on the applied stress. Using a linear regression of the creep data, the stress exponent is determined to be $n=7.0 \pm 0.2$. It should be noted that the stress exponent of 7 measured in this study is close to values of 7.3 and 6.8 measured for $\mathrm{Ti}-46 \mathrm{Al}-2 \mathrm{~W}-0.5 \mathrm{Si}$ and for Ti-48Al-2W-0.5Si [at.\%] alloys, respectively $[16,17]$. On the other hand, it is higher than the value of 5.8 measured by Lapin et al. [11, 12] for the same alloy creep tested at temperatures from 700 to $800^{\circ} \mathrm{C}$ and applied stresses ranging from 200 to $400 \mathrm{MPa}$ or that of 5 deter- 
mined by Lapin [18] for Ti-45.2Al-2W-0.6Si-0.7B [at.\%] and Parthasarathy et al. [19] for selected polycrystalline fully lamellar TiAl-based alloys. The obtained stress exponent is also higher than the experimentally measured and theoretically predicted values of about 5 for the creep controlled by dislocation climb in single-phase alloys [20].

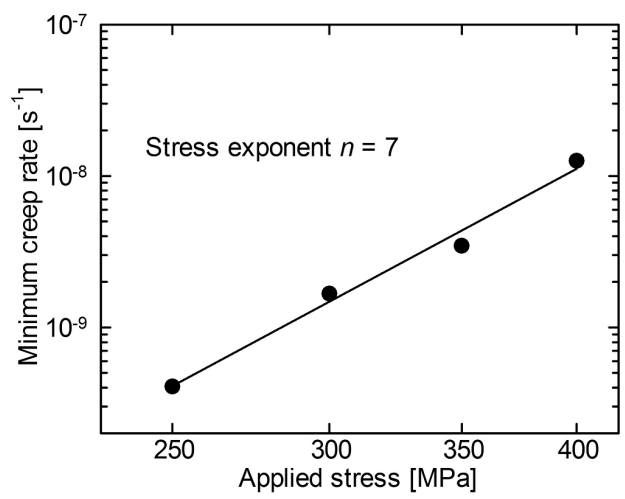

Fig. 3. Dependence of minimum creep rate on the applied stress at $700^{\circ} \mathrm{C}$.

The high stress exponent $n$ measured in this study requires a supplementary experimental technique to identify the creep controlling mechanism. In order to determine the creep mechanisms, the alloy was crept at $350 \mathrm{MPa}$ to a strain of about $2.8 \%$, which is slightly higher than that of $2 \%$ corresponding to a minimum creep rate and then the stress was abruptly decreased to $250 \mathrm{MPa}$.

Figure 4 shows the creep response of the alloy to this stress reduction.

It is clear that the stress reduction is followed by a zero creep stage and the creep at the new applied stress of $250 \mathrm{MPa}$ begins after an incubation period of $55 \mathrm{~h}$, as shown in Fig. 5. The presence of an incubation period of zero creep after the stress reduction indicates that creep is controlled by dislocation recovery where dislocation climb is rate-controlling process.

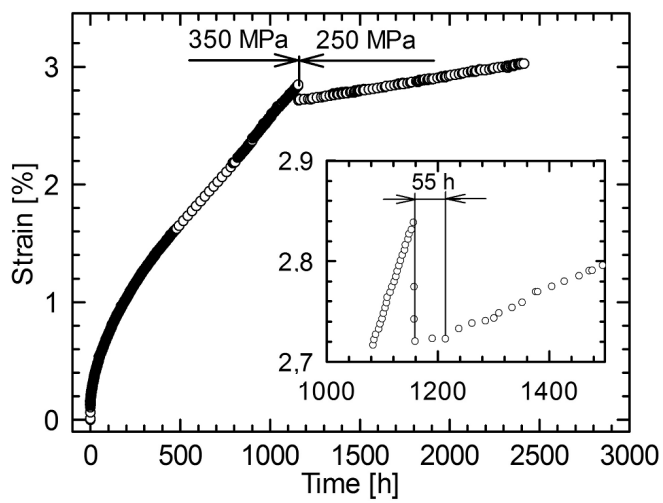

Fig. 4. Creep strain response to stress reduction from 350 to $250 \mathrm{MPa}$ at $700{ }^{\circ} \mathrm{C}$. The incubation period is indicated in the inset of the figure.

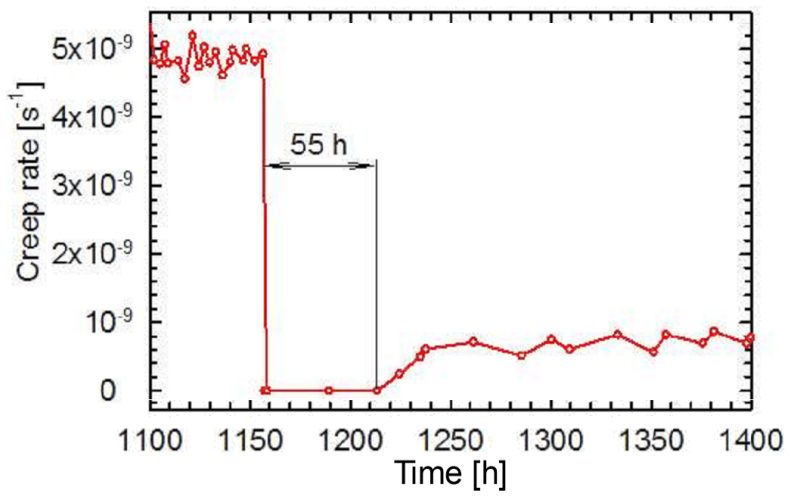

Fig. 5. Variation of average creep rate with time during stress reduction from 350 to $250 \mathrm{MPa}$ at $700^{\circ} \mathrm{C}$. The duration of zero creep stage is indicated in the figure.

Microstructural observations revealed that the creep of the specimens tested to strains corresponding to minimum creep rate is dominated by $1 / 2\langle 110]$ type ordinary dislocations, as seen in Fig. 6. The lamellar interfaces appear to effectively constrain deformation to the individual $\gamma$ lamellae with little evidence for direct transmission of dislocations under applied creep conditions. The dislocations in the thicker $\gamma$ lamellae tend to be elongated in the screw orientation and appear to be frequently pinned along their lengths. The dislocation segments form local cusps along the length of the dislocations. Such cusps are frequently associated with tall jogs on the screw dislocation segments [16]. The dislocation segments bowing between the jogs lie on parallel $\{111\}$ planes and the jogs themselves lie on a cross slip plane. As suggested by Appel [21], the jogs move by climb under the combined action of thermomechanical stresses and osmotic climb forces arising from the chemical potential of the excess of vacancies.

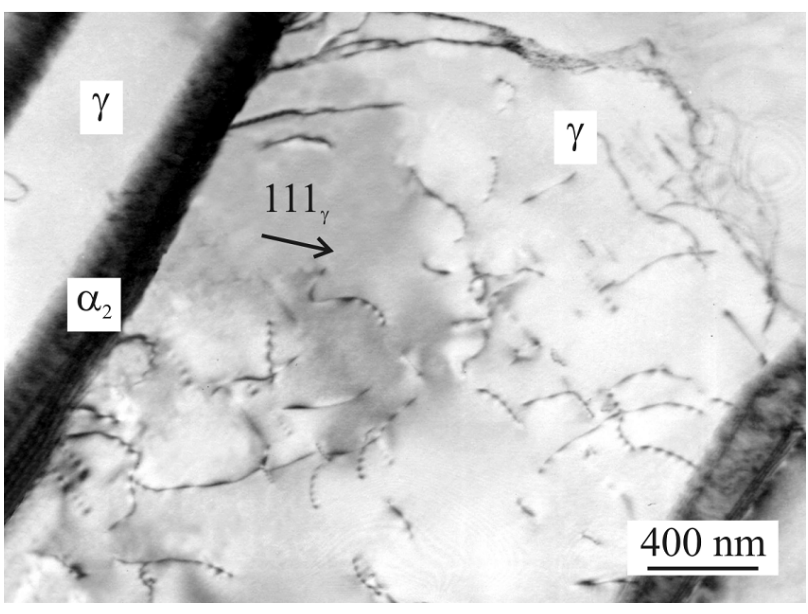

Fig. 6. TEM bright field micrographs showing the deformation microstructure of the creep specimens tested to a strain of $1.7 \%$ at $700{ }^{\circ} \mathrm{C} / 250 \mathrm{MPa}$ for $1372 \mathrm{~h}$, zone axis $[\overline{1} 10]_{\gamma}$. 
The stress necessary to move channelling dislocations within the $\gamma$ lamellae depends on the lamellar spacing. The decrease of lamellar spacing results in an increase of the bowing stress, which explains the low dislocation density observed within the thin $\gamma$ lamella shown in Fig. 6 . It should be noted that besides ordinary dislocations observed within the $\gamma$ phase, few mechanical twins were observed within some thick $\gamma$ lamellae and some $\gamma$ grains. The contribution of mechanical twinning to the overall measured creep strain is negligible at low strains corresponding to minimum creep rate but significantly increases in advanced stages of creep [22].

\section{Conclusions}

Controlling mechanisms of the creep deformation of a new cast air-hardenable $\mathrm{Ti}-46 \mathrm{Al}-8 \mathrm{Ta}$ [at.\%] were studied at $700{ }^{\circ} \mathrm{C}$. The creep curves show a primary creep stage which is directly followed by tertiary creep. During the primary creep stage the creep rate decreases with increasing strain. After reaching a minimum value, the creep rate increases with increasing strain. The power law stress exponent for the minimum creep rates is measured to be $n=7.0 \pm 0.2$. The presence of an incubation period of zero creep after stress reductions indicates that creep is controlled by dislocation recovery, where dislocation climb is probably the rate-controlling process. TEM investigations reveal that ordinary dislocations in the $\gamma$ matrix dominate the deformation microstructures at creep strains corresponding to minimum creep rate. The dislocations are elongated in the screw orientation and form local cusps, which are frequently associated with jogs on the screw segments of dislocations.

\section{Acknowledgments}

This work was financially supported by the Slovak Research and Development Agency under the contracts APVV-0434-10 and APVV-0009-07 and the Slovak Grant Agency for Science under the contract VEGA 2/0157/10. The authors would like to thank Dr. M. Dománková for the help with TEM analysis and U. Hecht from ACCESS (Germany) for providing the experimental material.

\section{References}

[1] J. Lapin, Z. Gabalcová, O. Bajana, Kovove Mater. 47, 159 (2009).

[2] W.J. Zhang, S.C. Deevi, Mater. Sci. Eng. A 362, 280 (2003).

[3] D. Hu, A.J. Huang, X. Wu, Intermetallics 15, 327 (2007).

[4] H. Saage, A.J. Huang, D. Hu, M.H. Loretto, X. Wu, Intermetallics 17, 32 (2009).

[5] J. Lapin, K. Frkán̆ová, Kovove Mater. 49, 243 (2011).

[6] J. Aguilar, A. Schievenbusch, O. Kättlitz, Intermetallics 19, 757 (2011).

[7] Q. Luan, Q. Duan, X. Wang, J. Liu, L. Peng, Mater. Sci. Eng. A 527, 4484 (2010).

[8] F. Appel, R. Wagner, Mater. Sci. Eng. R 22, 187 (1998).

[9] W.J. Zhang, S.C. Deevi, Intermetallics 10, 603 (2002).

[10] J. Lapin, Kovove Mater. 43, 81 (2005).

[11] J. Lapin, T. Pelachová, M. Dománková, Intermetallics 19, 819 (2011).

[12] J. Lapin, H. Staneková, Acta Phys. Pol. A 122, 453 (2012).

[13] H. Jiang, K. Zhang, X.J. Hao, H. Saage, N. Wain, D. Hu, M.H. Loretto, X. Wu, Intermetallics 18, 938 (2010).

[14] J. Aguilar, U. Hecht, A. Schievenbusch, Mater. Sci. Forum 638-642, 1275 (2010).

[15] J. Lapin, T. Pelachová, H. Staneková, M. Dománková, Kovove Mater. 48, 337 (2010).

[16] J. Lapin, Intermetallics 14, 115 (2006).

[17] V. Recina, D. Lundström, B. Karlsson, Metall. Mater. Trans. A 33A, 2869 (2002).

[18] J. Lapin, Scr. Mater. 50, 261 (2004).

[19] T.A. Parthasarathy, M.G. Mendiratta, D.M. Dimiduk, Scr. Mater. 37, 315 (1997).

[20] J. Čadek, Creep in Metallic Materials, Elsevier, New York 1988, p. 181.

[21] F. Appel, Intermetallics 9, 907 (2001).

[22] A. Dlouhý, K. Kuchařová, J. Březina, Mater. Sci. Eng. A 319-321, 820 (2001). 